\title{
eoría y prácticas de la interpretación
}

\section{Christian Carrier}

Expo Média Conseil,

Paris

Traducción: Sandrine Sol
Este texto tiene como objetivo dar a conocer los fundamentos teóricos para las prácticas de interpretación del patrimonio. Para ello, nos ha parecido necesario definir el concepto de interpretación y en qué contexto se utiliza.

Previamente, debe realizarse un ejercicio de interpretación... de la interpretación. En efecto, cada disciplina tiene su propia práctica de la interpretación y aunque sea útil un enfoque semántico, no es suficiente.

Las definiciones que con mayor frecuencia encontramos en los diccionarios son: "acción de explicar, de dar un significado claro a un signo o a un conjunto de signos oscuros, densos y complicados"; "acción de explicar lo que es oscuro o ambiguo en un texto, hecho, actitud, comportamiento...".

\section{¿Dónde empieza y dónde acaba la interpretación?}

Primera observación: la interpretación tiene siempre una doble dimensión: cultural y personal.

\section{La dimensión cultural:}

Cada grupo social produce unos valores, unos conocimientos, y un "saber-hacer". Cada grupo social tiene una historia, unas tradiciones que refuerzan los vínculos entre los individuos y un sentimiento de identidad. Las interpretaciones son más o menos homogéneas, coherentes, evolutivas, según la importancia (vivida) de la influencia de la educación, la familia, la comunidad étnica o religiosa, la corporación o el sindicato, el partido político, etc...

\section{La dimensión personal:}

La dimensión cultural se desdobla a su vez en una dimensión subjetiva. Depende si el individuo está siempre influido por el grupo social al que pertene- ce y constituye su referencia; en la práctica de la interpretación cada uno da un significado personal dentro de las numerosas posibilidades. La práctica de la interpretación está cargada de la sensibilidad y emotividad propia de cada uno y marcada por la experiencia personal !.

Segunda observación: toda interpretación se presta a la polémica ${ }^{2}$.

La adoptamos, la adaptamos o la rechazamos. En la interpretación, la certeza depende de la convicción, si no, de la creencia.

La interpretación no puede pretender encontrar en todos los casos una verdad objetiva o una respuesta de una exactitud científica. Esto es lo que nos enseña la práctica diaria ya que se habla de: falsa interpretación, interpretación errónea o error de interpretación, interpretación arbitraria, tendenciosa, fraudulenta, interpretación malévola, interpretaciones opuestas, contradictorias, contrasentido, malentendido etc...

Tercera observación: para algunos especialistas, esta dificultad, esta fragilidad del resultado de la interpretación, hacen de la práctica algo delicado, si no peligroso. Investidos de legitimidad-legitimidad científica, religiosa o ideológica...- quieren que su práctica sea exclusivamente suya. $Y$ existe la tendencia -real o simbólica- para quienes detentan el poder de querer controlar y orientar la manera en que sus conciudadanos, sus alumnos y sus fieles interpreten los mensajes y los acontecimientos. Para ellos, existen unas interpretaciones legítimas que son las únicas verdades. La convicción y la creencia es una y surge el peligro de intolerancia o de un sistema totalitario con censura e inquisición.

Del mismo modo, existe el riesgo de la evidencia. La evidencia suprime la necesidad de explicar, de interpretar. $Y$ esto suele ocurrir en nombre de la tradición, como si la antigüedad de un error constituyese una verdad incontestable... O simplemente porque la prueba está vinculada a la convicción o la 
Los dispositivos de interpretación del patrimonio están destinados a suscitar interés, provocar la emoción, permitir ir más allá de una mera reacción, incitar a la reflexión y a la imaginación, constituir unos conocimientos y contribuir a establecer valores que podrán ser compartidos por una comunidad.

creencia. En realidad, existen varias modalidades y niveles de interpretación.

\section{Sensación - percepción - interpretación}

Vamos a situarnos en varios contextos. El nivel más elemental: interpretar es dar un significado a lo que pertenece al mundo de la sensación que experimentamos a través de nuestros sentidos ${ }^{3}$ : da un significado a lo que vemos, oímos, tocamos, sentimos y probamos. También es prestar interés, dar un valor o quedarse indiferente a lo que percibimos, después de haber sido registrada la sensación y con posterioridad a una eventual reacción inmediata.

Tenemos un encadenamiento que se segmenta de la siguiente manera: sensación, percepción, emoción, interpretación de primer grado, que dará lugar al reflejo/reacción seguido eventualmente de un tiempo de reflexión y de una interpretación de segundo grado.

\section{Interpretación - reflejo- reacción}

Este esquema es válido en el comportamiento que observamos en el mundo animal, en tanto que el animal, ve, oye, siente y reacciona por reflejo, o bien se toma el tiempo de reflexionar para interpretar lo que percibe y adaptar su conducta a la interpretación que hace de esa sensación y de la situación en la que se encuentra. Para éste el reflejo es instintivo, está inscrito en el código genético de su especie, o aprendido condicionado por la enseñanza o la doma. ¡El reflejo de Pavlov no necesita más explicación!

Los seres humanos reaccionan igualmente por reflejo y lo hacen ante una situación determinada, un comportamiento o un modo de expresión. La reacción es inmediata, positiva o negativa, de interés, de entusiasmo, de rechazo o de aburrimiento o indiferencia. Ésta suele ser calificada de espontánea, lo que es discutible ya que el ser humano está también condicionado por su educación, su cultura, su entorno, su propia psicología, etc. La sensación, la percepción, la interpretación están pues siempre condicio- nadas en diversos grados por el contexto, la situación, lo vivido.

Para que haya interpretación, en el nivel de la percepción, es preciso que ésta sea integrada por la persona que la vive y que la analiza simultáneamente en la situación vivida, dentro de sus conocimientos previos -formados por el conjunto de sus experiencias y saberes- y de su potencial imaginario.

\section{Reflexionar - reconocer/imaginar- interpretar - actuar}

Si calificamos el reflejo o la reacción inmediata como el grado más elemental de interpretación, podemos decir que la interpretación de segundo grado empieza en cuanto hay una búsqueda de significado. Interpretar es, entonces, intentar, hacer comprensible lo que es complejo, complicado o ambiguo; es reconocer, comprender lo que es nuevo, lo que no es conocido y por lo tanto no puede ser reconocido; es situar la novedad percibida en relación a lo que conocemos o creemos reconocer o a lo que somos capaces de imaginar.

Percibimos en un contexto, en un momento y en un tiempo dado; interpretamos y hacemos uso o no del resultado de la interpretación. Por ejemplo, interpretamos un gesto, un comportamiento, un tono de voz, como agradable, hostil o indiferente ${ }^{4}$.

Propongo distinguir dos tipos de situaciones en las cuales se suele practicar la interpretación: la situación de comunicación y la de descubrimiento.

\section{La situación de comunicación}

Es la que analizó Aristóteles en el Peri-hermeneias: "Es interpretación cualquier sonido emitido por la voz y dotado de significados".

- Cualquier hecho del lenguaje entre un emisor y un receptor, empleando un código con su sintaxis y su vocabulario - sin olvidar el tono de la voz o las actitudes de los interlocutores ${ }^{5}$. 
- Cualquier sistema de signos intercambiado entre los interlocutores, así como los demás modos de comunicación tales como la mímica, los gestos, actitudes y comportamientos cuyas convenciones y tradiciones hay que conocer, estableciendo una distinción entre la producción consciente o inconsciente, voluntaria o involuntaria.

A partir de un gesto, de un comportamiento puede de igual manera percibirse -o creer percibirse- unos indicios que uno interpreta y después analiza para poder situarse. Un gesto o un comportamiento, claramente significativos dentro de una determinada cultura, de una tradición conocida, pueden ser codificados, lo que deja un estrecho margen de error a la persona que lo percibe. Esto no ocurrirá ante un comportamiento nuevo o en un contexto cultural diferente en el cual un gesto puede ser portador de un significado radicalmente diferente. Conocemos varios ejemplos. La lectura de las obras de Goffman y de Hall son particularmente ricas en informaciones y análisis sobre este tema.

Recordemos que para el semiólogo, el signo es una producción voluntaria, consciente, dirigida a un destinatario y realizada para comunicar una información. El signo utiliza un código, o una convención. Para ser percibido e interpretado, se vale de un soporte material, gráfico, gestual o sonoro. El código o la convención son, supuestamente, conocidos por el destinatario que deberá descodificar, reconocer para proceder a una interpretación lo más exacta posible. No obstante, en numerosas situaciones, ajenas al proceso de comunicación entre dos interlocutores, se considera como signo a aquello a lo que se le atribuye un significado. Es lo que llamaremos situación de descubrimiento.

\section{La situación de descubrimiento}

Es el caso, por ejemplo, de la interpretación que el científico o el cazador hacen de un rastro o de unas huellas dejadas en el suelo por un animal. No se trata de comunicación porque no hay ninguna intención de comunicar por parte del animal. No hay código; sin embargo el rastro se lee como si fuera un signo conocido y reconocido y, por consiguiente, identificable, explotable e interpretado con un margen de error muy pequeño o como si fuera un signo desconocido que puede interpretarse con un margen de error variable según las circunstancias.

Tomemos otro ejemplo, la interpretación del cielo para establecer una previsión meteorológica. No puede hablarse de comunicación, tampoco de códigos, sino de un conjunto de elementos visibles interpretados como signos por la persona que sabe reconocer los criterios de tal o cual fenómeno atmosférico y sus consecuencias probables o posibles.

Veamos ahora el ejemplo del vestigio arqueológico.
¿La primera operación consiste en reconocer que se trata verdaderamente de un vestigio! Éste es enigmático o reconocible y según los criterios utilizados podrá verificarse o no. La interpretación se verá facilitada si el hallazgo tuvo lugar durante una excavación metódica o dentro de un contexto ya conocido. El conjunto de conocimientos previos acumulados por el arqueólogo durante sus estudios y durante su experiencia profesional, serán determinantes a la hora de "construir" su interpretación.

Nos enfrentamos en estos tres ejemplos a una realidad material, sensible, a veces estable (el vestigio) y a veces efímera (el cielo).

El análisis que posibilitará la interpretación dependerá de la práctica semiológica. El indicio (o conjunto de indicios) es el punto de partida de una hipótesis que se comprueba y apoya (con más o menos solidez) sobre referencias a un saber y/o una experiencia adquirida antes de llegar a una conclusión, a una convicción, a la formación de un conocimiento. En consecuencia, se nombra, se califica, se clasifica, se ordena dentro de una categoría.

Analicemos ahora el ejemplo de la investigación policial. Su objetivo es conseguir un conjunto de pruebas a partir de indicios, de testimonios. Un rastro, una huella se analizan como un indicio.

A partir de este primer análisis -que es similar a descifrar- se construye una o un conjunto de hipótesis que serán comprobadas según diversos métodos y criterios de referencia y cuya legitimidad es más o menos reconocida según los casos.

Las hipótesis comprobadas contribuyen a constituir una prueba $\mathrm{o}$ incitan a seguir en la búsqueda de un nuevo elemento, a reunir nuevos indicios, nuevos testimonios. El conjunto de ellos contribuirá a la construcción teórica de la prueba o a una simple convicción ("la íntima convicción" de los miembros del jurado).

\section{Otras acciones de interpretación}

Materializar, dar vida a lo que está latente o a lo que es virtual. Desde este punto de vista interpretar es hacer sensible lo que está en estado latente o virtual. Hacer sensible y perceptible es dar una nueva forma de existencia: existencia sonora, con el lenguaje o la música; existencia visible, con el dibujo u otro grafismo o bien con la escultura o cualquier otro volumen como la maqueta.

El artista que hoy en día denominamos conceptual, es aquel que da una existencia material al concepto y por consiguiente lo interpreta dándole forma y eventualmente volumen.

En el caso de la partitura musical es el que la ejecuta quien después de haberla descifrado la interpreta ofreciéndola al auditorio. Hay una producción vocal 
o instrumental para hacer audible la música imaginada por el compositor.

La música puede ser de igual manera "memorizada" lo que le da otro tipo de existencia virtual hasta que no se haga sensible.

El intérprete no se conforma sólo con ejecutar la partitura, le da un toque personal, sensible y técnico, eventualmente cargado de tradición, de efectos de escuela o de moda.

De la misma manera, podríamos hablar de las interpretaciones teatrales o cinematográficas, teniendo en cuenta todos los elementos que se materializan en la representación. El timbre de la voz, los comportamientos y los actitudes, los vestidos de los actores, el decorado, la iluminación, el ritmo de la escenografía tienen a veces tanto peso como el contenido de los diálogos.

En la antigüedad, cuando los augures interpretaban los sueños, los astros, el vuelo de las aves, las vísceras de los animales sacrificados... veían, leían signos, presagios...

De igual modo, evocaremos lo que no tiene una realidad material, lo que es producto del lenguaje o fruto de la memoria: por ejemplo el mito, objeto inmaterial tipo, destinado por naturaleza a la interpretación y más aún cuando tiene una parte de enigma. Observaremos que hace referencia a menudo a datos que la memoria humana no ha conservado o cuya significación se ha perdido con el tiempo.

Las artes figurativas, como las artes escénicas, suelen dar a los mitos unas interpretaciones materiales, visibles y audibles.

Sigmund Freud, el psicoanalista, da un significado al sueño que le ha sido relatado oralmente por el paciente analizado y, por consiguiente, ya interpretado en la expresión de su lenguaje tal y como lo estudió Lacan. Si leyéramos el informe del análisis, tendríamos igualmente la posibilidad de interpretarlo nosotros también.

\section{La interpretación de los textos}

La lectura de un texto conlleva otro nivel de interpretación. El contexto en el que leemos es ya diferente de la relación interpersonal.

Intervienen el tipo de texto que leemos, el objetivo que perseguimos leyendo: ¿buscamos abandonarnos al placer de la lectura o buscamos una información que necesitamos de manera imperativa?

La interpretación de los textos literarios da lugar a unos interminables debates contradictorios y a numerosas polémicas sobre las super-interpretaciones ${ }^{6}$ posibles.
Los textos jurídicos ${ }^{7}$ presentan las mismas dificultades. Las leyes establecen reglas generales que no pueden prever todas las hipótesis particulares, unas veces omiten una de las hipótesis, en otras no la regulan de forma satisfactorias y en otras su texto es oscuro o ambiguo; en todos los casos estas lagunas deben ser resueltas por la interpretación.

Sería conveniente recordar las categorías o (clases) de interpretación ${ }^{8}$ que acostumbramos a identificar en la práctica.

La interpretación literal (o textual) que se limita a la estricta aprehensión del texto (en el caso del arte consistirá en la simple descripción de la obra; en arqueología en la mera descripción del vestigio...).

La interpretación exegética que intenta extraer las intenciones del autor.

La interpretación teleológica que consiste en situar la interpretación realizada en relación a la norma vigente y a su finalidad.

Observemos, de paso, que si la lectura de un poema o de una novela puede dar lugar a una desviación de la interpretación, no representa sin embargo, los mismos peligros que una lectura errónea de las instrucciones de uso o de empleo de una máquina o de un medicamento. No puede medirse con un mismo rasero las consecuencias de la exactitud de la interpretación. Unas instrucciones de uso no deben dar lugar a interpretación: indican un procedimiento a seguir rigurosamente si quieren evitarse errores y sus consecuencias.

No olvidemos la interpretación alegórica frecuente en la historia del pensamiento (la Cábala que es la interpretación alegórica de la Biblia) y en la historia del Arte.

\section{La interpretación de las imágenes}

El ejemplo de la iconografía y su interpretación es particularmente interesante. Nos puede emocionar el contenido o la estética de una imagen grabada o pintada. Podemos apreciar la calidad del trabajo. Pero la verdadera comprensión necesita tener conocimiento del programa iconográfico que ha guiado la realización de la obra: tema bíblico o mitológico, histórico o poético, ilustración de un relato o transcripción simbólica, alegoría, metáfora visualizada... Las claves de comprensión deben ser conocidas para poder permitir una interpretación que se aproxime lo más posible a las intenciones del autor - o del cliente. Volvemos a encontrar el código o la convención.

En cambio, el pintor realista interpreta el paisaje que tiene ante sus ojos, al igual que el retratista interpreta a su modelo. En ambos casos se trata de una representación en dos dimensiones de una realidad de tres con la práctica de la perspectiva como interpretación del espacio real. 
Según la elección del fondo ${ }^{9}$, del momento y de la distancia en la que opera, el fotógrafo da una interpretación de lo que ha fotografiado. De igual manera, el revelado del negativo será una operación de interpretación.

La interpretación fotográfica militar es un ejemplo interesante porque se calcan sobre un mapa las informaciones recogidas por el fotógrafo. En este caso la interpretación es sinónimo de selección de elementos visibles, localizados al objeto de ser utilizados.

La radiografía, el escáner, el T.A.C. son otros ejemplos de interpretaciones con dos niveles. La máquina realiza una interpretación programada que el médico debe a su vez interpretar, identificando los síntomas con el fin de establecer un diagnóstico.

El modelo es el ejemplo típico de interpretación utilizada para la exposición, porque permite visualizar lo invisible. Conocemos, por ejemplo, esta verdadera escultura que representa la estructura del A.D.N. Igualmente, podemos considerar cualquier ampliación o miniaturización como una realización que permite hacer visible lo que el ojo no puede percibir. La maqueta es el ejemplo más conocido.

Con la película o el montaje audiovisual, también tenemos la posibilidad de interpretar un proceso demasiado largo para poder ser seguido y entendido en tiempo real mediante la utilización de las secuencias, de la forma eléptica o del flash-back.

Podríamos multiplicar los ejemplos y profundizar en los análisis, pero hemos comprobado que: toda producción de teoría o de relato es una representación de la realidad, y toda elaboración o aplicación de un método es una práctica interpretativa.

La interpretación es un acto complejo que para ser analizado necesita dar respuestas a una serie de preguntas:

- ¿Qué es lo que interpretamos?

- ¿Quién interpreta? (¿Cuál es la legitimidad y la autoridad del interprete?)

- ¿Para quién se hace la interpretación? (¿Para qué tipo de interlocutor?).

- ¿Cuáles son los objetivos de la interpretación?, ¿Para qué uso?

- ¿Qué utilización se va a hacer de los resultados de la interpretación?

- ¿Cuál es el contexto de lo que interpretamos?

Asimismo, ¿en qué contexto interpretamos?

(¿Cuál es la situación de interpretación: material, física, temporal, pero también psicológica, institucional...?).
- ¿Cómo interpretamos?

- ¿Cuál es el dispositivo de interpretación? ¿Con qué método?

- ¿A qué referencias recurrimos? ¿En qué se basa la interpretación?

\section{La interpretación del patrimonio}

Veamos, ahora, algunos aspectos de la interpretación del patrimonio. Previamente, es indispensable hacer las siguientes distinciones entre:

- La interpretación que practican los especialistas en sus trabajos de investigación, generando unas series de hipótesis, problemáticas y conocimientos. La interpretación se orienta hacia el objeto patrimonial.

- Los dispositivos de interpretación, destinados el público, para suscitar interés, provocar la emoción, permitir ir más allá de la reacción en el sentido estricto, incitar a la reflexión y a la imaginación, constituir unos conocimientos y contribuir a establecer unos valores que podrán ser compartidos por una comunidad.

La realización de estos dispositivos pone en juego varios tipos de interpretación.

Proponemos tomar en consideración tres tipos de interpretación que pueden coexistir: la interpretación emocional (la interpretación estética o "estetizante"), la interpretación ideológica, y la interpretación instrumental (interpretación operativa).

\section{La interpretación emocional}

Denominamos interpretación emocional a toda representación que busca provocar una sensación en el espectador, provocar su emotividad y que despierte su emoción -la sola contemplación del objeto de estudio no es suficiente para provocar la emoción-. Diríamos que hay una interpretación emocional en toda presentación que ponga de relieve un aspecto estético o lúdico.

Podemos enumerar determinados efectos que se buscan (les invito a completar esta lista): efecto de majestuosidad, efecto de sacralización (o al contrario, efecto de trivialidad), efecto de amontonamiento, efecto de serie, efecto almoneda, efecto bazar, efecto anticuario, efecto joyería; efecto de dramatización con iluminación y sombras o aparición del objeto en un entorno oscuro, efectos sonoros, efectos olfativos; no acabaríamos nunca la lista... 10

Pero la interpretación emocional ha empezado con la realización del decorado de la exposición, con el diseño del mobiliario de presentación, con la elección de la tipografía de los escritos, de los materia- 
les, de los colores, de la iluminación con todo lo que une o aísla, lo que glorifica, sacraliza o trivializa, con todo lo que evoca.

Todos estos efectos cambian, y a veces recargan el objeto de estudio de significados que pueden llegar a ser como parásitos. Pueden imaginarse las desviaciones del género y los efectos perversos que pueden provocar algunas escenografías o algunas museografías que suelen ser motivo de debates contradictorios y apasionados.

¿Hasta qué punto estas emociones sentidas por el visitante pueden suscitar el interés, la curiosidad? ¿Hasta dónde estas emociones pueden orientar y facilitar su comprensión? ¿Hasta qué punto estas emociones pueden dar una consistencia a su memorización basándola sobre una experiencia personal vivida, lo que no se limita a una simple "absorción de conocimientos" más o menos bien organizados?

A veces, se confundirá la interpretación emocional con la interpretación ideológica por las "manipulaciones" II de los sistemas de valores que hacen referencia al nacionalismo, al patriotismo, a las etnias, a las memorias identificativas, a las conmemoraciones, a la religión, a la moral, etc.

\section{La interpretación ideológica}

Advertencia previa: no debe reducirse el adjetivo "ideológico" a la dimensión política o propagandística; aun cuando se trate para nosotros de no ignorar su eventual presencia, más o menos discreta.

Llamo interpretación ideológica a todo dispositivo que acompaña la presentación del objeto de estudio, a todo instrumento que intenta dar una explicación, histórica, económica, sociológica, religiosa o cualquier otro.

Es interpretación ideológica toda explicación o demostración que depende de un sistema de pensamiento, generalmente de carácter global, que intenta situar al objeto de estudio dentro de un conjunto coherente construido o reconstruido o a todo instrumento que tiende a construir un conjunto comprensible por el público, por deducción o analogía, con la ayuda de la metáfora o de la alegoría.

Hacer una interpretación ideológica es construir un relato que integra el objeto de estudio, es construir una explicación, una cronología, un entorno, un contexto. Es narrar, contar, construir una ficción alimentada, dentro de lo posible, con las garantías científicas que se imponen para legitimar lo apropiado de la actuación.

Es ideológico toda integración en una explicación relevante de la nación, de la etnia, de la religión, tan adecuada como sea, todo lo que depende de lo simbólico, de la convicción, de la fe, del museo de las ideas, aunque presente aspectos contradictorios y minoritarios.

\section{La interpretación instrumental 12}

Llamo interpretación instrumental a toda presentación que tiene como objetivo ayudar al espectador en su capacidad de percibir y de ver mejor, y que tiene como fin ayudarle a descifrar la complejidad de lo visible. Esto incluye todos los instrumentos, todos los medios destinados a aprender, a distinguir, a aislar dentro de un conjunto confuso, dentro de una realidad compleja, las huellas, los vestigios, los indicios, los signos, los elementos estilísticos, los estratos históricos etc. Tambien todos los dispositivos de ayuda a la visibilidad, ayudas a la legibilidad, a la comprensión, y de ayudas a la construcción de lo imaginario y de la memoria. Sin olvidar todo lo que ayuda a aprender a comprender los conjuntos, a leer el paisaje, el urbanismo, la arquitectura, los monumentos, los conocimientos, las técnicas empleadas, las cadenas de producción, etc.

Para poder localizar y situar un elemento dentro de un conjunto complejo, existen numerosos soportes de interpretación instrumental:

- La reconstitución analítica de un objeto o de un conjunto o de un contexto inicial.

- Los cambios de escala, los modelos reducidos y las ampliaciones.

- Las maquetas, animadas o inmóviles, o interactivas, según los casos.

- Los audiovisuales y las películas que descomponen el movimiento, las fases del proceso evolutivo o los elementos sucesivos de una cadena de producción..

- Los esquemas.

- Los planos esquemáticos, y los planos extraordinariamente detallados.

- Los dossiers fotográficos.

- Los escritos en su conjunto.

- Los diversos instrumentos interactivos cuando facilitan la representación y la comprensión de un sistema.

La interpretación instrumental es necesaria para poder leer y por consiguiente ver los estratos verticales y horizontales de nuestras ciudades.

La interpretación iconográfica es, por ejemplo, indispensable para acceder a la comprensión mínima del arte de la Edad Media, del Renacimiento, del Barroco, etc.

Algunos de estos mecanismos de interpretación existen ya en diversos museos que se han preocupa- 
do por la mediación cultural, la divulgación científica o didáctica. Pero con la democratización de las visitas prácticas a los museos, la interpretación instrumental se ha vuelto una necesidad.

\section{En conclusión}

Interpretar es para el hombre la manera más común de producir un significado.

El presente es siempre el punto de partida para la interpretación del pasado. Lo que refuerza el vínculo con el pasado es el objeto patrimonial. Con razón podemos hablar de historicidad de la interpretación.

El lenguaje es el "medio" fundamental de la experiencia interpretativa. Cuando no se utiliza el lenguaje, se hace necesario encontrar un sustituto.

El objeto patrimonial (obras de arte, documentos, instrumentos, simples objetos o incluso monumentos) "expuesto" no habla por sí solo. Hemos tenido que constituirlo (interpretarlo) como objeto patrimonial, museográfico, de exposición. La interpretación interviene en todos los niveles de la investigación científica y de la comunicación.

La mirada sobre el objeto patrimonial suscita siempre una reacción, una emoción en la persona que lo contempla. La reacción y la emoción pueden ser positivas -por ejemplo de admiración-o negativas -por ejemplo de indiferencia-. Más allá de la reac- ción inmediata, el objeto patrimonial puede dar pie a un interrogante, a una reflexión, a una contemplación, que puede potenciar o desencadenar el contexto y el modo de la presentación.

De hecho, la simple exposición es de por sí una práctica de interpretación del objeto presentado.

Los instrumentos a través de los cuales podemos entender los objetos patrimoniales, los dispositivos de presentación y de interpretación son las denominadas "teorías materializadas". Éstas funcionan como fichas de lectura que pueden ser revisadas.

El pensamiento interpretativo interviene cuando nos encontramos en presencia de signos. Estos signos son ambiguos, a veces por torpeza, aunque en la mayoría de las veces por exceso de riqueza.

El pensamiento interpretativo se desarrolla entrelazando una presencia y una ausencia (en particular en ausencia, la mayoría de las veces, del contexto original).

El pensamiento interpretativo supone la existencia de una cierta tradición.

Dentro de la realización de los mecanismos de exposición, la dificultad principal reside en la diversidad de las tradiciones a las que se refieren los que "producen" la interpretación del objeto patrimonial; confrontándolas con las tradiciones de los profanos: los visitantes... 
I. Se puede llegar hasta el delirio de la interpretación, lo que se constata en el ámbito psiquiátrico cuando un enfermo atribuye a un hecho real una significación inexacta. Su razonamiento saca unas inducciones o deducciones erróneas de los hechos reales según el estado en qué se encuentra.

La alucinación puede considerarse como una interpretación delirante...

2. Nietzche en su carta de 20 agosto I 888 a Kartl Fuchs escribe: "presuponer que fundamentalmente hay una interpretación exacta me parece psicológica y experimentalmente falso."

3. Habría que añadir: lo que presentimos, o pensamos presentir.

4. El error de interpretación es una función esencial del relato, escrito o escenificación, creando situaciones dramáticas o cómicas,... según la interpretación que le da el autor y según la manera que lo viven y lo interpretan el lector o el espectador.

5. Llamar intérprete al que traduce un texto de un idioma a otro nos hace confundir traducción e interpretación. Pero a veces es difícil ver la diferencia.

6. Umberto Eco en: Interpretation and overinterpretation, Cambridge University Press 1992.

7. "La importancia de la interpretación es extraordinaria en la aplicación del Derecho y su recto uso es indispensable para los jueces y para los letrados." En Enciclopedia Universal Europea-Americana, Madrid, 1926...
8. Savigny señala cuatro elementos de la interpretación: gramatical, lógico, histórico y sistemático.

9. En 1920, Kouletchov llevó a cabo unos experimentos muy reveladores: fotografió una cara impasible cambiando los "fondos" -o segundos planos- de la foto: escena de combate, anochecer al borde del mar.... la misma cara aparecía según los casos trágica o tranquila... es lo que se denomina el "efecto Kouletchov".

10. La observación de las "figuras de retóricas visuales" utilizadas para la presentación de los productos en un escaparate es un ejercicio particularmente eficaz para desarrollar sus capacidades de análisis. Presenta la ventaja de ser también lúdico.

II. No olvidemos las prácticas de la publicidad, dentro de las mismas manipulaciones con el empleo de palabras o imágenes "de choque", utilizadas como señales -estímulo cuyo objetivo es provocar un reflejo y una reacción inmediata, estrechando al máximo posible el margen de interpretación. Observar, en particular, la utilización de la palabra "auténtico"..

12. Interpretación instrumental, o instrumentalizada u operativa. 